University of Nebraska - Lincoln

DigitalCommons@University of Nebraska - Lincoln

Faculty Publications from the Department of

Electrical and Computer Engineering

Electrical \& Computer Engineering, Department

1997

\title{
Estimation of Surface Snow Properties Using Combined Millimeter-Wave Backscatter and Near-Infrared Reflectance Measurements
}

\author{
Ram M. Narayanan \\ University of Nebraska-Lincoln \\ Sandy R. Jackson \\ University of Nebraska-Lincoln
}

Follow this and additional works at: https://digitalcommons.unl.edu/electricalengineeringfacpub

Part of the Electrical and Computer Engineering Commons

\begin{abstract}
Narayanan, Ram M. and Jackson, Sandy R., "Estimation of Surface Snow Properties Using Combined Millimeter-Wave Backscatter and Near-Infrared Reflectance Measurements" (1997). Faculty Publications from the Department of Electrical and Computer Engineering. 120.

https://digitalcommons.unl.edu/electricalengineeringfacpub/120

This Article is brought to you for free and open access by the Electrical \& Computer Engineering, Department of at DigitalCommons@University of Nebraska - Lincoln. It has been accepted for inclusion in Faculty Publications from the Department of Electrical and Computer Engineering by an authorized administrator of DigitalCommons@University of Nebraska - Lincoln.
\end{abstract}


Published in International Journal of Infrared and Millimeter Waves 18:5 (1997), pp. 959-990. Copyright (C) 1997 Plenum Publishing Corporation. Used by permission.

Submitted February 6, 1997

\title{
Estimation of Surface Snow Properties Using Combined Millimeter-Wave Backscatter and Near-Infrared Reflectance Measurements
}

\author{
Ram M. Narayanan and Sandy R. Jackson \\ Department of Electrical Engineering Center for Electron-Optics, \\ University of Nebraska-Lincoln, Lincoln, Nebraska 68588-0511, U.S.A.
}

\begin{abstract}
Knowledge of surficial snow properties such as grain size, surface roughness, and free-water content provides clues to the metamorphic state of snow on the ground, which in turn yields information on weathering processes and climatic activity. Remote sensing techniques using combined concurrent measurements of near-infrared passive reflectance and millimeter-wave radar backscatter show promise in estimating the above snow parameters. Near-infrared reflectance is strongly dependent on snow grain size and free-water content, while millimeter-wave backscatter is primarily dependent on free-water content and, to some extent, on the surface roughness. A neural-network based inversion algorithm has been developed that optimally combines near-infrared and millimeter-wave measurements for accurate estimation of the relevant snow properties. The algorithm uses reflectances at wavelengths of $1160 \mathrm{~nm}, 1260 \mathrm{~nm}$ and $1360 \mathrm{~nm}$, as well as co-polarized and cross-polarized backscatter at a frequency of $95 \mathrm{GHz}$. The inversion algorithm has been tested using simulated data, and is seen to perform well under noise-free conditions. Under noise-added conditions, a signal-to-noise ratio of $32 \mathrm{~dB}$ or greater ensures acceptable errors in snow parameter estimation.
\end{abstract}

Keywords: inversion, multisensor, neural network, remote sensing, snow properties 


\section{Introduction}

Snow is an important environmental parameter that has farreaching impact on a variety of military and civilian functions, such as mobility, trafficability, and economic well-being [I]. Snow is also a key component that has a major influence on climate, both on the local and global scales [2], as well as on agriculture due to its hydrological implications [3]. Various remote sensing techniques have been developed for rapid, consistent, and timely monitoring of snow properties on an areal scale [4], [5], and these techniques continue to be refined and enhanced.

Snow is a complex medium consisting of ice, air, water vapor, and, when wet, water. It is spatially and temporally variable, and may be heterogeneous within the same layer. After snow is deposited following a snowfall, the particle shapes are modified by metamorphism [6]. In order to attain a state of thermodynamic equilibrium, the snow particles tend to form larger clusters thereby minimizing the surface area-to-volume ratio. Other processes that can alter the shape and size of snow particles are temperature gradients brought about by solar radiation, compaction due to pressure, and repeated melt-freeze cycles. Wind speed near the snow surface also affects the snow particle packing and snow surface roughness. A comprehensive snow crystal classification method has been developed to characterize snow based on various weathering processes [7].

New freshly-fallen fine-grained snow typically has average grain diameters between $0 . I$ and $0.25 \mathrm{~mm}$, and densities in the range 0.1 $0.2 \mathrm{gm} / \mathrm{cc}$. Aged snow, formed after a few days of temperature gradient metamorphism, has grain sizes in the range $0.2-1.5 \mathrm{~mm}$ and densities in the range $0.25-0.45 \mathrm{gm} / \mathrm{cc}$. Repeated melt-freeze cycles cause the snow particles to increase in size to between $0.5-3 \mathrm{~mm}$, and densify to between $0.2-0.5 \mathrm{gm} / \mathrm{cc}$ [8]. The free-water content of snow can vary over a wide range, and can attain values as high as $30 \%$, with a transition region around $15 \%$ where the particle shape asymmetry factor changes dramatically [9]. However, such high values usually occur when the snow overlies an impermeable substrate, and in most cases, free-water content in snow remains less than $5-6 \%$ [I0]. A free-water content of greater than $0 \sim$ is indicative of snow melting brought about by temperatures at or above the freezing point, while surface or sub-surface temperatures below the freezing point are indicative of dry snow (free-water content of $0 \%$ ). 
Results of a comprehensive ground truth study of snow indicates that the surface roughness is of the order of snow crystal dimensions, and generally varies between $0.3-3.5 \mathrm{~mm}$, with a standard deviation that is comparable to its mean value [11]. Thus, it is recognized that clues to weathering processes and current climatic conditions can be inferred from measurements of grain size, surface roughness, and free-water content of snow.

This paper describes a method for remote estimation of the above snow parameters using near-infrared reflectance and millimeterwave backscatter. In Section II, the various models used in the simulation study are described, and a justification provided for the choice of the appropriate sensor parameters. In Section III, the neural-network inversion technique is developed and its performance when applied to simulated data under both noise-free as well as noise-added conditions is assessed. Section IV summarizes and concludes.

\section{Models Used in the Simulation}

The optical and electromagnetic properties of snow depend on various factors, such as its grain size distribution, porosity, density, surface roughness, free-water content, and layering characteristics. The sensitivity of snow's optical and electromagnetic characteristics to its physical parameters depends largely on the wavelength or frequency of the radiation used for probing.

\section{A. Near-Infrared Reflectance}

A commonly used model to predict the visible and near-infrared reflectance of snow is based on the so-called Delta-Eddington approximation to the radiative transfer theory [12]. This approximation is valid for a medium that shows strong forward scattering [13]. For large particle diameter-to-wavelength ratios of over I00 (as is the case here), asymptotic approximations yield accurate results with minimal computational complexity [14]. The single particle coalbedo, $\mathrm{W}$, and the single particle asymmetry factor, $G$, are calculated from [15]:

$$
W=0.5+0.5 \exp \left(-0.84 K_{s} D\right)
$$

and

$$
G=0.87 \exp \left(-K_{s} D\right)+0.97\left[1-\exp \left(-K_{s} D\right)\right]
$$


where $\mathrm{K}_{s}$ is the effective absorption coefficient of snow and D is the grain diameter. For dry snow, $\mathrm{K}_{s}=\mathrm{K}_{i}$, where $\mathrm{K}_{i}$ is the absorption coefficient of ice, while for wet snow, we use a volume-weighted formula to express $\mathrm{K}_{s}$ as:

$$
K_{s}=W_{w} K_{i}+\left(1-W_{w}\right) K_{w}
$$

where $\mathrm{K}_{w}$ is the absorption coefficient of water, and $\mathrm{W}_{w}$ is the volume fraction of water.

The directional hemispherical reflectance, $\mathrm{R}$, is then calculated at a specific angle of incidence, $\theta$, from [13]

$$
R=\frac{4(B-P A)}{3\left(1+\frac{2 P}{3}\right)}
$$

where the other terms in the expression for $\mathrm{R}$ are given by

$$
\begin{aligned}
& P=\left[\frac{3\left(1-W_{s}\right)}{1-W_{s} G_{s}}\right]^{1 / 2} \\
& A=3 W_{s} Y_{0}\left[\frac{1+G_{s}\left(1-W_{s}\right)}{4\left(1-K_{s}^{2} Y_{0}^{2}\right)}\right] \\
& B=3 W_{s} Y_{0}\left[\frac{1+3 G_{s}\left(1-W_{s}\right) Y_{0}^{2}}{4\left(1-K_{s}^{2} Y_{0}^{2}\right)}\right] \\
& K=\left[3\left(1-W_{s}\right)\left(1-W_{s} G_{s}\right)\right]^{1 / 2} \\
& W_{s}=\frac{\left(1-G^{2}\right) W}{\left(1-G^{2} W\right)} \\
& G_{s}=\frac{G}{1+G} \\
& Y_{0}=\cos \theta
\end{aligned}
$$

The theoretical results generally agree with measurements of snow reflectance in the near-infrared region [16]. In general, the reflectance decreases with increasing free-water content as well as increasing grain size. However, the decrease in reflectance due to increasing free-water content has been attributed not to the presence of water per se, but to the increased particle size due to clusters that form in wet, unsaturated snow [17]. Nevertheless, the dependence of reflec- 
tance on free-water content is more pronounced at wavelengths in the range 1000-1400 nm. Furthermore, impurities such as soot have minimal impact on the reflectance of snow at wavelengths higher than $1000 \mathrm{~nm}$ [18]; thus, this wavelength range is optimal for obtaining high sensitivity to changes in free-water content and grain size.

A technique for simultaneous estimation of free-water content and grain size using near-infrared reflectance at three optimally selected wavelengths in the 1000-1400 $\mathrm{nm}$ range has been developed recently [8], and this method has been used by us in our inversion algorithm. Using the reflectance values at three wavelengths, two reflectance ratios are derived: one which is primarily dependent on average grain size and relatively independent of free-water content, and another which shows high sensitivity to free-water content. Based on the spectral reflectance curves, the reflectance ratio $S_{1}$, given by $R(1160) / R(1260)$, where $R(\lambda)$ is the near-infrared reflectance at a wavelength of $\lambda \mathrm{nm}$, is found to be independent of free-water content, and dependent only on grain size. The selection of the above wavelengths ensures that the effective absorption coefficients (and hence, the reflectances) are virtually the same for water, thereby minimizing the dependence on free-water content. On the other hand, the ratio $S_{2}$, given by $R(1260) / R(1360)$, has been determined to be strongly sensitive to free-water content, owing to the identical absorption coeffcients of ice at these wavelengths. However, this ratio $\mathrm{S}_{2}$ also depends on the grain diameter.

\section{B. Millimeter-Wave Backscatter}

Models and measurements of snow backscatter at millimeter wavelengths (frequencies in the range $30-300 \mathrm{GHz}$ ) indicate that the radar reflectance is primarily dependent on snow free-water content and surface roughness and, to a lesser extent, on snow density and grain size [19]. The backscatter from snow is dominated by volume scattering, especially at low free-water contents, and surface scattering can usually be neglected at frequencies of $95 \mathrm{GHz}$ and above [20]. Furthermore, both co-polarized as well as cross-polarized backscatter values decrease as the free-water content increases, and this lowering results from the higher absorption coeffcient as the water content increases. It has also been observed that the rate of decrease of the cross-polarized backscatter of snow with free-water content is higher than the rate of decrease of the co-polarized component, and this has been attributed to a reduction in multiple scattering effects as the snow becomes absorptive [20]. 
The effect on snow surface roughness on millimeter-wave backscatter is rather inconclusive, primarily due to our inability to accurately quantify snow surface roughness and its spatial variability. Since the wavelengths in this frequency range vary between 1 and $10 \mathrm{~mm}$, surface roughness values of this order are thought to impact snow backscatter. Measurements show varied effects: one study shows that snow backscatter increases with surface roughness [21], whereas another study shows a slight lowering in backscatter with increasing roughness [19]. A third study observed that the backscatter decreased for dry snow, but increased for wet snow with increasing roughness [22], while a fourth study concluded that the backscatter decreases with roughness at incidence angles of less than $35^{\circ}$, while this trend was reversed at higher incidence angles [23]. Our conclusion is that there is a weak dependence of snow backscatter at millimeter wavelengths on surface roughness.

Although various models exist to describe the snow backscatter at millimeter wavelengths, we used a simple empirical model that shows decoupled dependences on free-water content and surface roughness. This model was developed initially for G-Band based on an extensive set of field measurements [24], and further extended to W-Band based on an independent set of measured data [25]. According to this model, the backscatter coefficient, $\sigma^{0}$, is of the form

$$
\sigma^{0}=\frac{A \cos ^{B} \theta 10^{-C M v}}{\sigma_{s}^{D}}
$$

where $\theta$ is the angle of incidence, $M_{v}$ is the "effective" free-water content in percent, $\sigma_{s}$ is the surface roughness in $\mathrm{mm}$, and $\mathrm{A}, \mathrm{B}, \mathrm{C}$, and D are empirically fitted parameters that depend on frequency and polarization combination. The above formula is valid in the range $10^{\circ} \leq \theta$ $\leq 85^{\circ}, 0 \% \leq \mathrm{M}_{v} \leq 20 \%$, and $0.5 \mathrm{~mm} \leq \sigma_{s} \leq 2 \mathrm{~mm}$. The "effective" freewater content is computed from the measured values in each snow layer weighted by a linear weighting function that serves to emphasize the effect of the top layers. Although simplistic, this model does capture the effects of the relevant snow properties on its backscatter characteristics, and generally agrees with data within limits of experimental error. The best-fit values of the four constants appearing in the model are shown in Table I. 
Table I. Best-Fit Constants for Snow Millimeter Wave Backscatter Model

\begin{tabular}{clllll}
\hline $\begin{array}{c}\text { Frequency } \\
(\mathrm{GHz})\end{array}$ & Polarization & $\mathrm{A}$ & $\mathrm{B}$ & $\mathrm{C}$ & $\mathrm{D}$ \\
\hline \multirow{2}{*}{95} & $\mathrm{CO}(\mathrm{VV} / \mathrm{HH})$ & 2.00 & 2.65 & 0.09 & 0.60 \\
& $\mathrm{CROSS}(\mathrm{VH} / \mathrm{HV})$ & 0.77 & 2.57 & 0.14 & 0.33 \\
215 & $\mathrm{CO}(\mathrm{VV} / \mathrm{HH})$ & 4.68 & 3.22 & 0.23 & 1.50 \\
& CROSS (VH/HV) & 2.00 & 3.45 & 0.46 & 2.00 \\
\hline
\end{tabular}

\section{Neural Network Inversion Technique}

\section{A. Basis for Algorithm Development}

The inversion technique for snow surface properties that has been developed requires ratios based on measured near-infrared reflectance and millimeter-wave backscatter values as its inputs. In the near-infrared region, measured reflectances at 1160, 1260, and 1360 $\mathrm{nm}$ wavelengths were used to compute two ratios: $\mathrm{S}_{1}$ and $\mathrm{S}_{2}$, given by

$$
\begin{aligned}
& S_{1}=\frac{R(1160)}{R(1260)} \\
& S_{2}=\frac{R(1260)}{R(1360)}
\end{aligned}
$$

where $R(\lambda)$ is the reflectance at a wavelength of $\lambda \mathrm{nm}$.

In the millimeter-wave region, the co-polarized and cross-polarized backscatter values at a frequency of $95 \mathrm{GHz}$ were used, primarily due to factors such as availability of components, low atmospheric absorption, and the theoretical prediction of negligible dependence of backscatter at this frequency on grain size [21]. From these backscatter values, the depolarization ratio, $\mathrm{D}_{R^{\prime}}$ was computed using

$$
D_{R}=\frac{\sigma_{x}^{0}}{\sigma_{\mathrm{c}}^{0}}
$$

where $\sigma^{0}{ }_{c}$ is the co-polarized backscatter and $\sigma^{0}{ }_{x}$ is the cross-polarized backscatter. 
The assumed angle of incidence for the near-infrared as well as millimeter-wave backscatter was $15^{\circ}$, although the inversion algorithm can be developed for any angle. Furthermore, it is assumed that the near-infrared and millimeter-wave footprints were co-registered in a preprocessing step, and that the pixel sizes were virtually identical.

In order to investigate the functional relationships between the selected ratios and variability in the physical parameters of snow, a total of 10,000 values of the reflectance and backscatter values were generated in each case. These values were generated as follows. For the near-infrared reflectance, the dominating physical parameters are the free-water content and grain diameter. The reflectance was computed for 100 values of free-water content in the range $0-20 \%$ at increments of $0.2 \%$, and 100 values of grain diameter in the range $0-2 \mathrm{~mm}$ at increments of $0.02 \mathrm{~mm}$. The millimeter-wave backscatter was calculated for 100 values of free-water content in the same range as above, and for 100 values of surface roughness in the range $0-2 \mathrm{~mm}$ at increments of $0.02 \mathrm{~mm}$. Values of parameters outside the range of validity of the empirical equations, although used, are not applicable in the final in- version. From these values, the ratios $S_{1}$, $S_{2}$, and $D_{R}$ were computed. Plots of these ratios as a function of one parameter showing the range of variation brought about by changes in the second parameter were used to ascertain the sensitivity of each ratio.

Figure 1 (a) shows the dependence of $S_{1}$ on the free-water content, with the range of variations due to variations in grain diameter shown as errorbars. The errorbars indicate values that tie within \pm 1 standard deviation. It is observed that the ratio is relatively insensitive to free-water content, as expected from theory. Figure l(b) shows the dependence of $S_{1}$ on grain diameter; as expected, we see a strong linear relationship on which the free-water content variation has minimal effect.

Figures 2(a) and 2(b) show the dependence of $S_{2}$ on free-water content and grain diameter. As expected, there is a strong dependence on free-water content, although the grain diameter variations affect this ratio somewhat. The dependence on grain diameter is, however, slight and not as strong as in the case of $\mathrm{S}_{2}$. Also, this dependence is not as robust to changes in free-water content as $S_{2}$. 


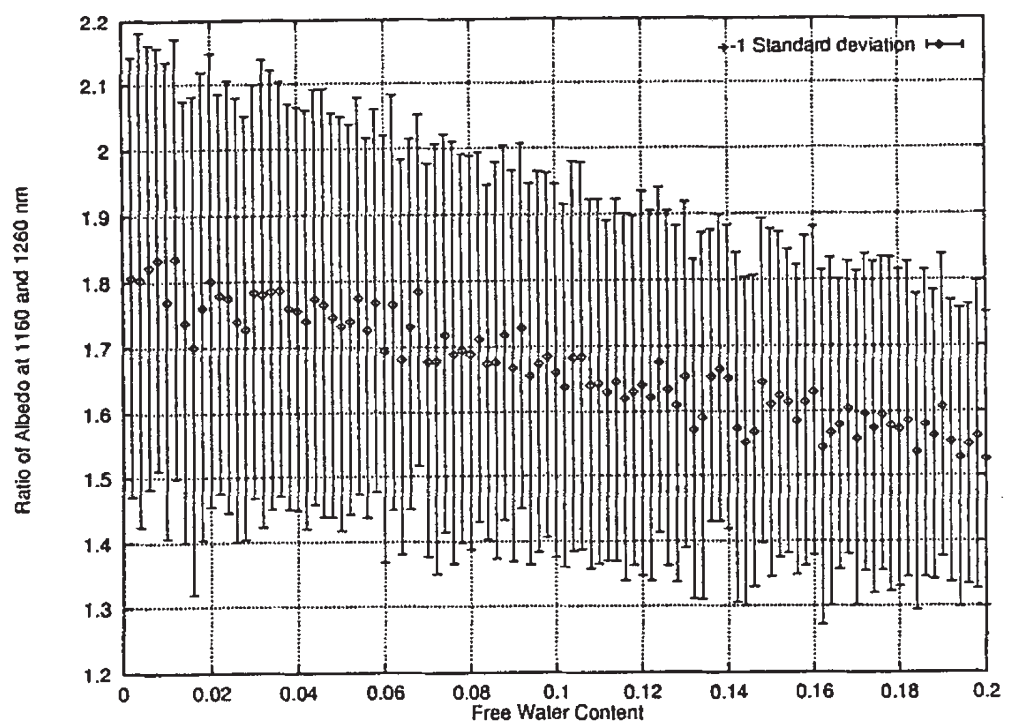

(a)

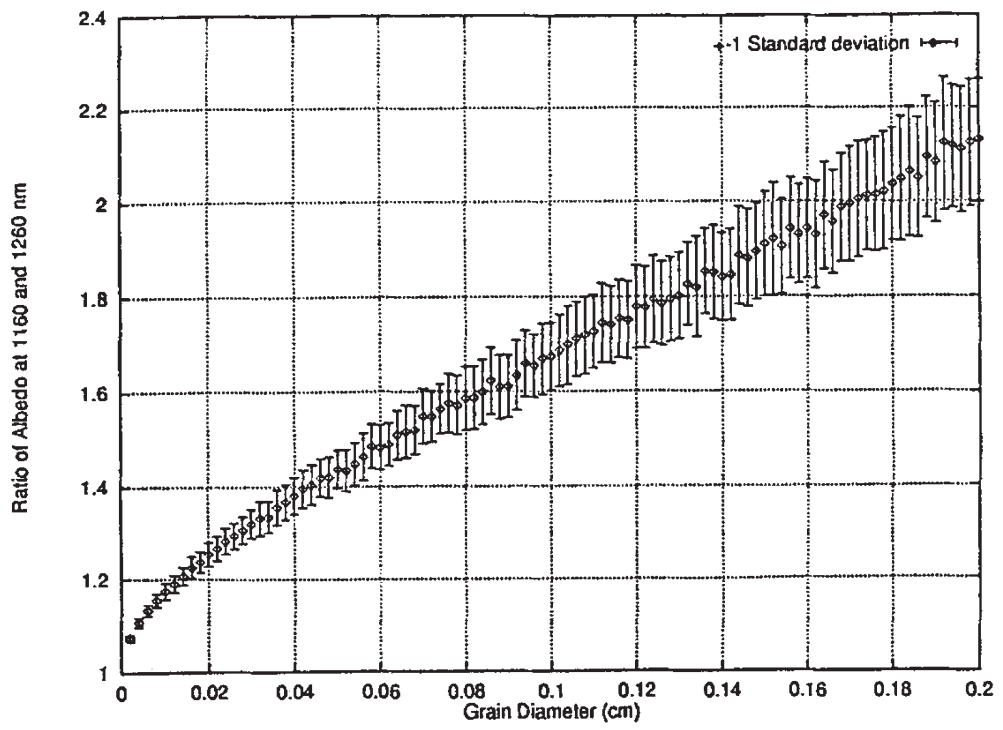

(b)

Figure 1: Dependence of reflectance ratio $S_{1}$ on (a) free-water content, and (b) grain diameter. 


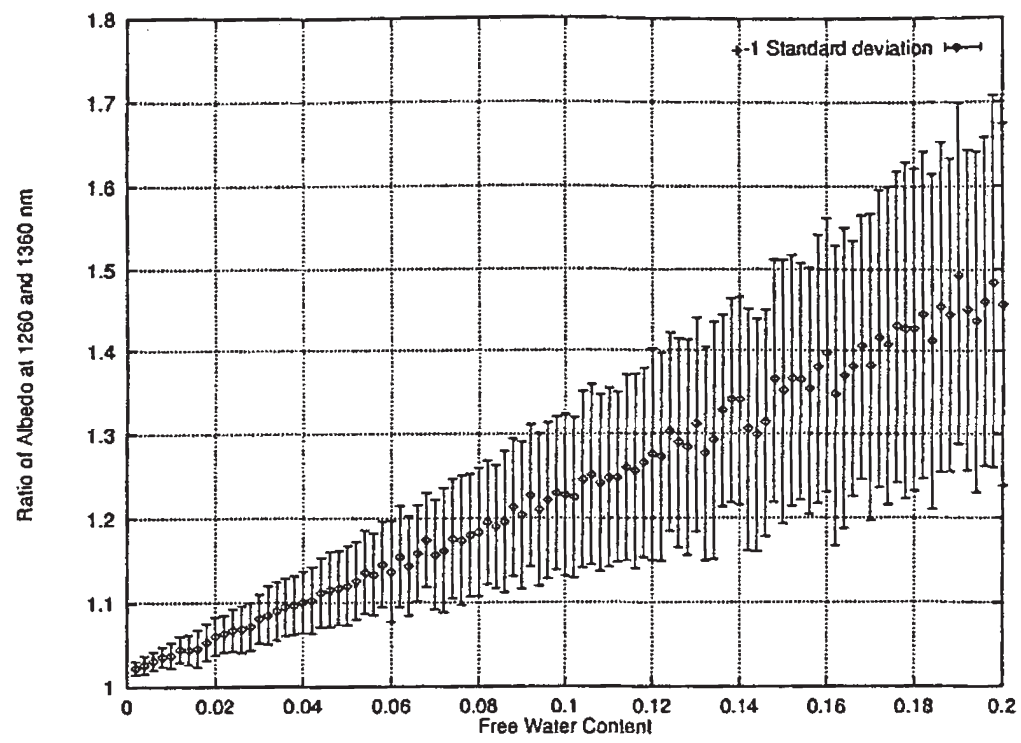

(a)

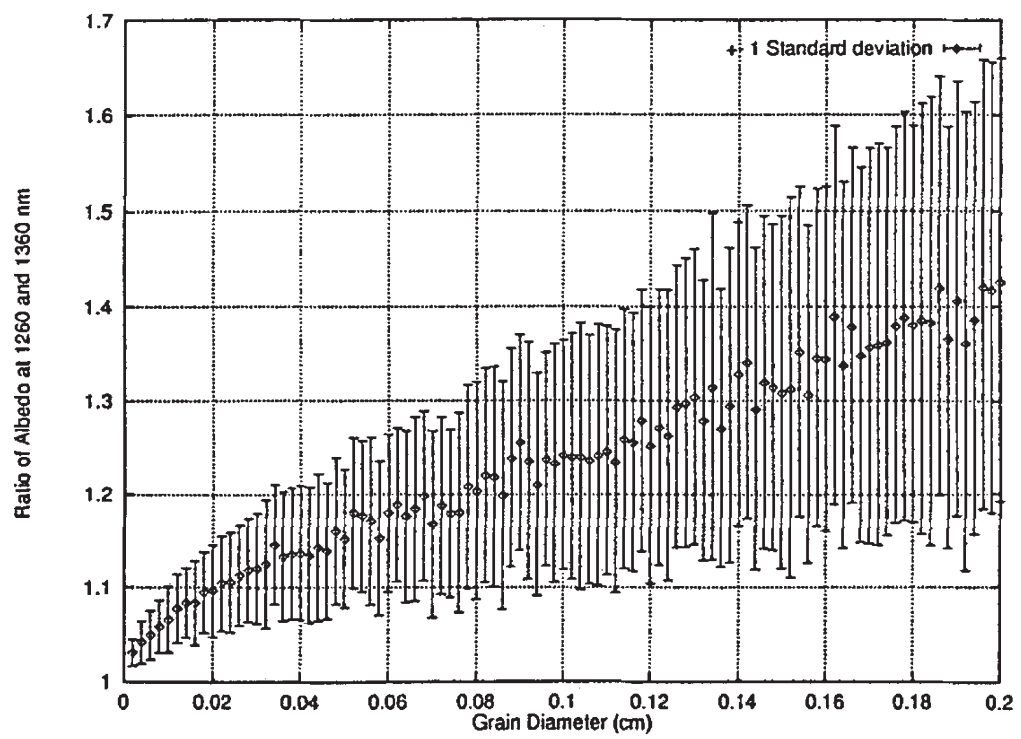

(b)

Figure 2: Dependence of reflectance ratio $S_{2}$ on (a) free-water content, and (b) grain diameter. 
Figure 3(a) shows the dependence of $\mathrm{D}_{R}$ on the free-water content. The effects of surface roughness variations reduce at higher moisture. Figure $3(b)$ shows the dependence of $D_{R}$ on surface roughness, and we observe the strong effects of variations in free-water content. The positive correlation of depolarization ratio to the surface roughness is expected due to the increase in the diffuse scattering brought about by roughening.

\section{B. Neural Networks Fundamentals and Considerations}

Artificial neural networks emulate the human brain in various applications, such as classification and inversion. Several elementary processing units are connected in parallel, and the knowledge of the relationships or memory is stored in the strength of the connections, or weights, of the interconnecting units. A neural network performs the function of a massively parallel distributed processor that can store and use experimental knowledge [26]. The neural network consists of several elementary processing units called nodes, which are usually summing junctions. The input to a node may be some measurement value, a discernible feature of an object, or an output from a previous stage, or layer. The connections or links between nodes are weighted, allowing for information storage, values of which can be adjusted to allow the network to learn. An example of a basic element of a neural network is shown in Figure 4. The output, y, can be expressed in general, as

$$
y=b+\sum_{i=1}^{N} w_{i} x_{i}
$$

where $\mathrm{b}$ is the bias, $\mathrm{w}_{i}$ is the weight of the $\mathrm{i}$-th link, $\mathrm{x}_{i}$ is the input from the i-th link, and $\mathrm{N}$ is the total number of links to the node. The output of a node is usually processed by a transfer function called an activation function. A commonly used activation function is the logistic function, $\mathrm{f}(\mathrm{y})$ given by

$$
f(y)=\frac{1}{1-\exp (-y \sigma)}
$$

which is bounded in the interval [0,1], and is continuously differentiable, making the neural network amenable to learning. This processed output becomes the input to the next node. 


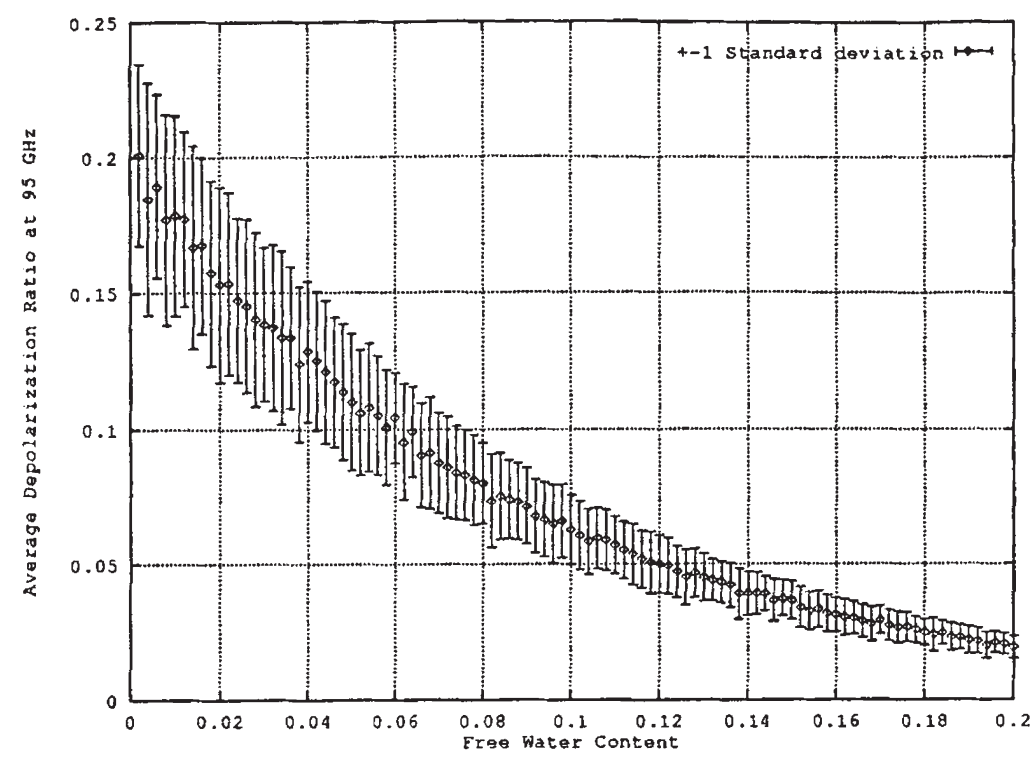

(a)

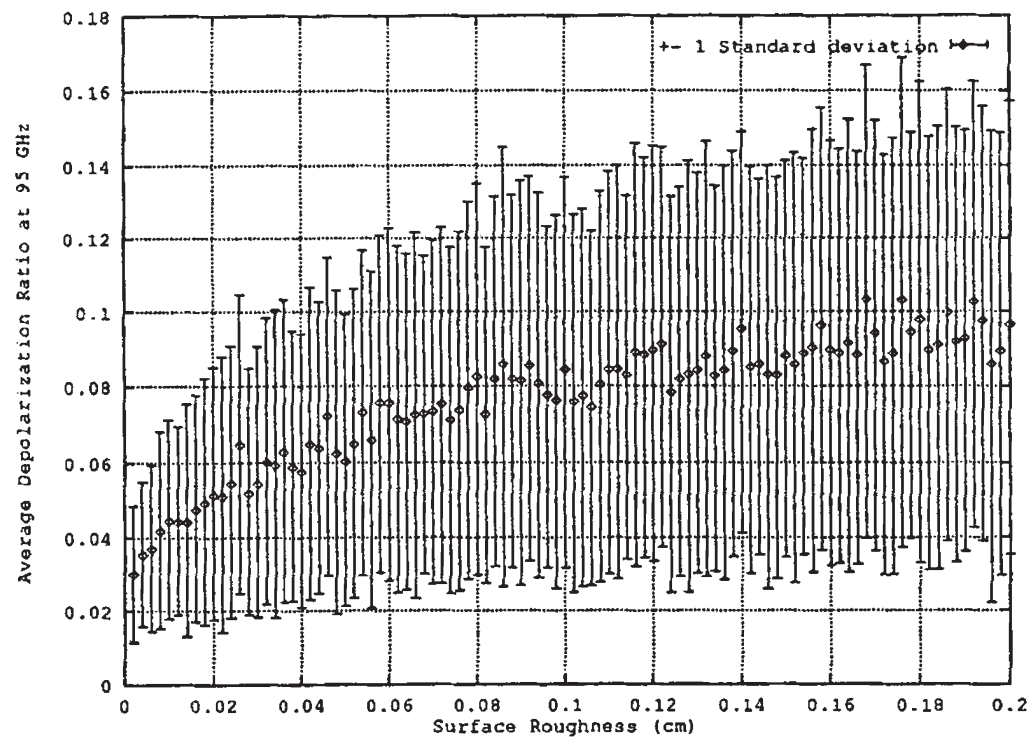

(b)

Figure 3: Dependence of depolarization ratio $D_{R}$ on (a) free-water content, and (b) surface roughness. 


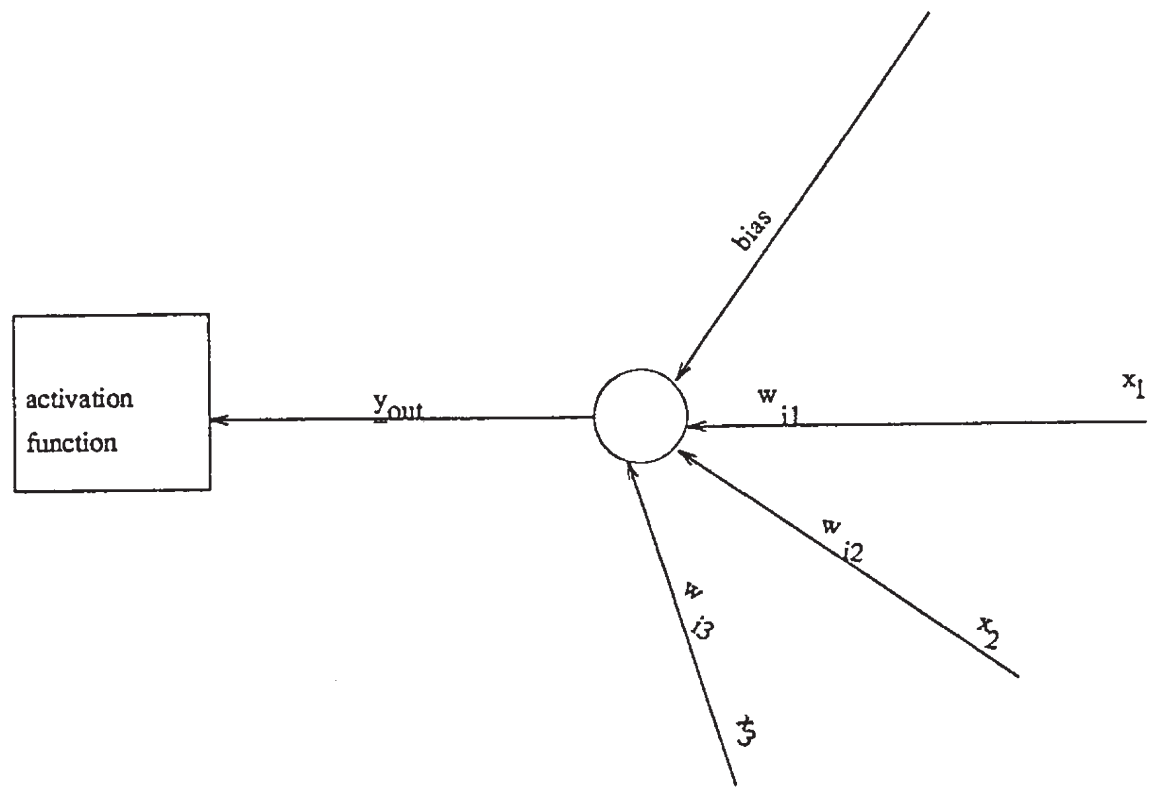

Figure 4: Example of the basic elements of a neural network. 
The functionality of a node is determined by its location within the network. A node in the first layer is an input node, which accepts inputs from the outside world. Each input node receives one input, does not usually perform any processing, and uses the identity function as the activation function. In a multi-layer feed-forward topology, outputs from a previous layer are fed to each node of the next layer. There might be many such intermediate layers in the network, called hidden layers.

Finally, the results of the network are presented at the output layer, with one node for each output.

Training the neural network involves adjustment of the weights, and one method to accomplish this using a gradient descent technique is the backpropagation algorithm [27]. The idea behind this method is that the error gradient is in the direction of maximum error, and any change that occurs in a direction opposite to the gradient optimally reduces the error. The error function used is based on a Euclidean metric, such as the mean squared error (MSE). The backpropagation algorithm attempts to minimize the MSE by adjusting the weights.

Neural network inversion techniques can be broadly classified into two types: explicit inversion (eg., [28]) and implicit inversion (eg., [29]). The explicit inversion algorithm directly relates the effect to the cause, and works well when the mapping between the two is one-to-one. The implicit inversion algorithm solves the forward problem (i.e, cause $\rightarrow$ effect), and then uses a priori knowledge to constrain the estimates. Although the implicit inversion technique is more complicated, the inverted estimates have lower errors compared to the explicit inversion technique applied to the same dataset. It is possible, however, to use the explicit inversion technique by performing judicious mathematical operations on the data to ensure that the one-to-one mapping indeed exists between cause and effect. In our case, use of the ratios $\mathrm{S}_{1}, \mathrm{~S}_{2}$, and $\mathrm{D}_{R^{\prime}}$ rather than reflectance or backscatter values, yields the one-to-one relationship, thereby permitting us to employ and exploit the simpler explicit inversion technique.

The neural network topology for snow parameter inversion developed by us is shown in Figure 5. The network consists of an input layer, an output layer, and two hidden layers. The input layer has three nodes consistent with the number of inputs $\left(\mathrm{S}_{1}, \mathrm{~S}_{2}\right.$, and $\left.\mathrm{D}_{R}\right)$, and the output layer has three nodes consistent with the number of outputs (free-water content, surface roughness, and grain diam- 


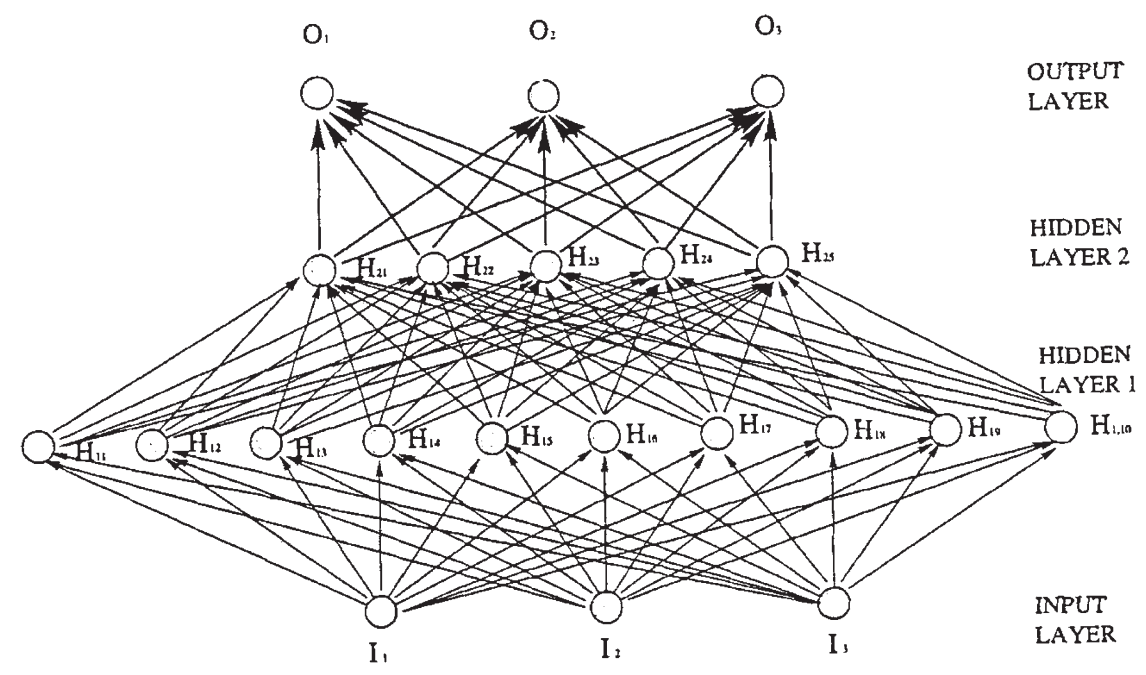

Figure 5: Neural network topology for snow parameter inversion. 
eter). Hidden layer 1 has ten nodes, while hidden layer 2 has five nodes. The use of two hidden layers resulted in accelerating the network learning process to a learning rate of 0.2 , without causing oscillations inherent in a single hidden layer network. Training samples were created using the models described in Section II, and were generated by incrementing each input parameter in 0.001 increments (Note that the range of variation in free- water content in absolute units, surface roughness in $\mathrm{cm}$, and grain diameter in $\mathrm{cm}$ is between 0 and 0.2; thus 20,000 training samples were created for each parameter). With a training rate of 0.2 and with 10,000 initial training samples, the network yielded a sum squared error (SSE) per output unit of 1.0 in about 60 iterations, and an SSE of approximately 0.17 in 300 iterations. At this point, the learning rate was changed to 0.1 (slower rate of learning) and the network trained with the remaining 10,000 training samples. This resulted in an SSE of 0.08 after 500 iterations, as shown in Figure 6 . The absence of oscillations in the convergence can also be noted.

The final results of the training exercise are tabulated in Tables II-IV. In these tables, weights of the links connecting various layers are shown. In these tables, $\mathrm{H}_{i j}$ is the $\mathrm{j}$-th node in the $\mathrm{i}$-th hidden layer, $\mathrm{I}_{i}$ is the $\mathrm{i}$-th component of the input vector, and $\mathrm{O}_{i}$ is the $\mathrm{i}$-th node in the output layer. The input nodes are: $\mathrm{I}_{1}=\mathrm{S}_{1}, \mathrm{I}_{2}=\mathrm{S}_{2}$, and $\mathrm{I}_{3}=\mathrm{D}_{R^{\prime}}$ while the output nodes are: $\mathrm{O}_{1}=$ free-water content, $\mathrm{O}_{2}=$ surface roughness, and $\mathrm{O}_{3}=$ grain diameter. 


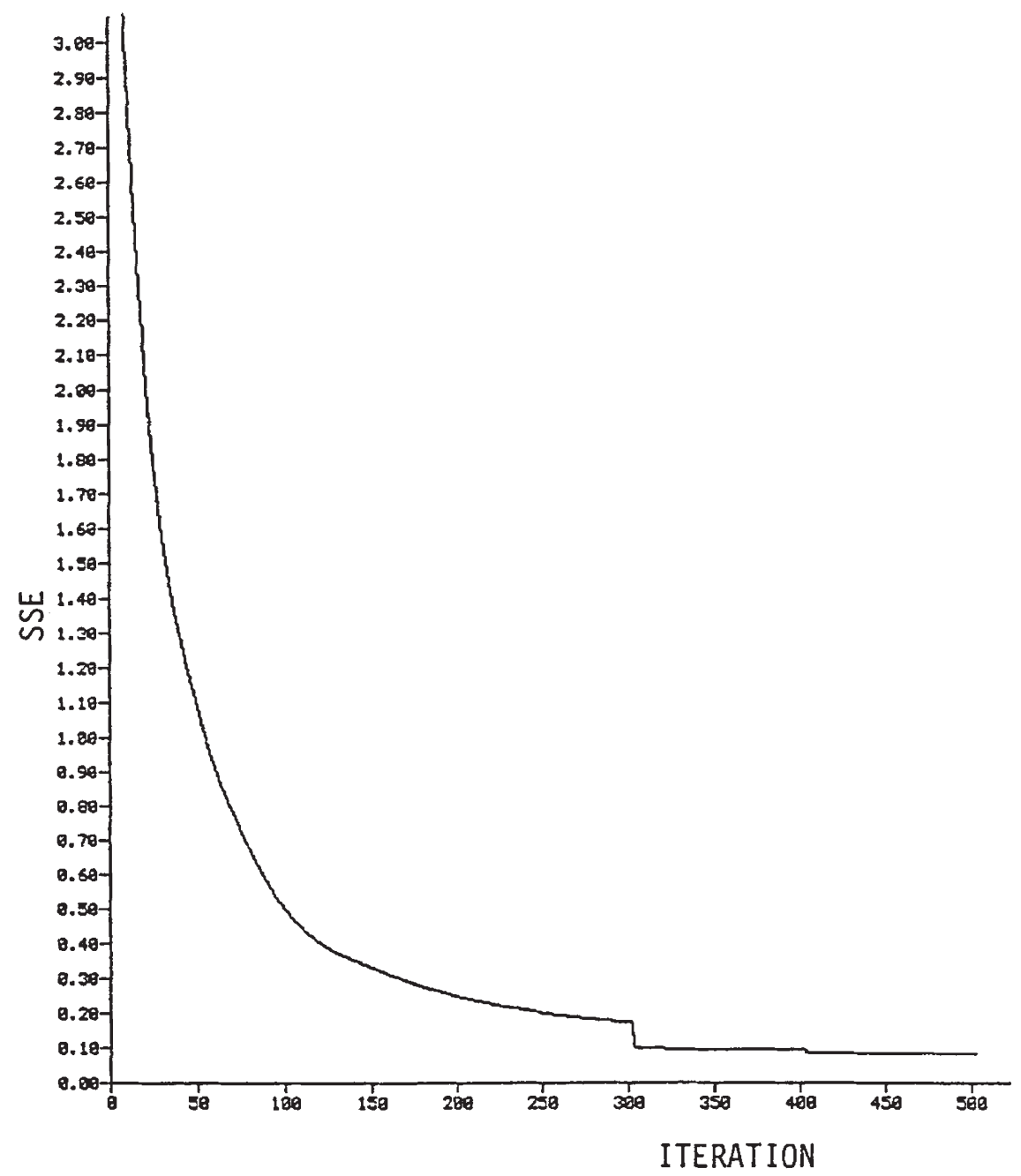

Figure 6: SSE per output unit as a function of number of iterations. The learning rate was 0.2 until the 300 th iteration, after which it was reduced to 0.1 . 
Table II. Weights from Input Layer to Hidden Layer 1

\begin{tabular}{lcccc}
\hline & & \multicolumn{3}{c}{ Weights from } \\
\cline { 3 - 5 } To & Bias & $\mathrm{I}_{1}$ & $\mathrm{I}_{2}$ & $\mathrm{I}_{3}$ \\
\hline $\mathrm{H}_{11}$ & 1.41999 & -2.07874 & 0.15234 & 2.60848 \\
$\mathrm{H}_{12}$ & 3.35004 & 0.23567 & -2.29779 & 12.2711 \\
$\mathrm{H}_{13}$ & 3.45566 & -7.02662 & 2.61167 & -1.66015 \\
$\mathrm{H}_{14}$ & -1.66611 & -2.13173 & 2.61857 & 13.4807 \\
$\mathrm{H}_{15}$ & -1.33606 & -1.07135 & 0.22342 & 1.21531 \\
$\mathrm{H}_{16}$ & 6.77108 & -0.66785 & -6.41409 & 3.71156 \\
$\mathrm{H}_{17}$ & 1.29454 & -5.74292 & 3.69721 & -11.0861 \\
$\mathrm{H}_{18}$ & 2.71456 & 2.01950 & -4.37032 & -1.89033 \\
$\mathrm{H}_{19}$ & 2.35570 & -0.74812 & -0.44336 & -5.44943 \\
$\mathrm{H}_{1} 10$ & -4.56065 & 5.90642 & -0.94133 & -2.22744 \\
\hline
\end{tabular}




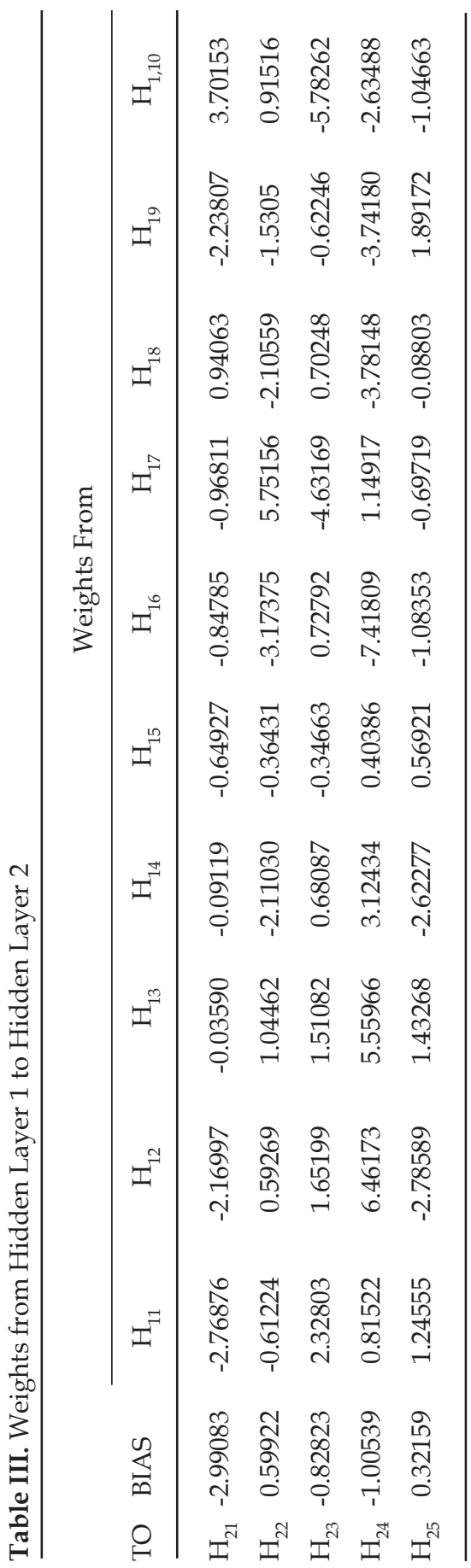


Table IV. Weights from Hidden Layer 2 to Output Layer

\begin{tabular}{llrrrrr}
\hline & & \multicolumn{5}{c}{ Weights from } \\
\cline { 3 - 7 } To & Bias & $\mathrm{H}_{21}$ & $\mathrm{H}_{22}$ & $\mathrm{H}_{23}$ & $\mathrm{H}_{24}$ & $\mathrm{H}_{25}$ \\
\hline $\mathrm{O}_{1}$ & 0 & -0.16059 & -0.05910 & -0.71052 & 0.76565 & 1.13824 \\
$\mathrm{O}_{2}$ & 0 & 1.69470 & -2.10317 & -3.54736 & 4.61264 & 2.67360 \\
$\mathrm{O}_{3}$ & 0 & 1.14005 & 0.11656 & 0.00965 & -0.00570 & -0.30152 \\
\hline
\end{tabular}

\section{Inversion Results}

The inversion of the snow parameters was performed first under noise-free conditions, i.e., from simulated reflectance and backscatter values obtained from the models, to test the inversion effectiveness. Next, the inversion was evaluated under various noise-added cases, in order to mimic realistic scenarios.

(1) Noise-Free Conditions: Under noise-free conditions, the inversion algorithm showed promising results. For each inverted parameter, we computed the mean value of the inversion, as well as the standard deviation and the total range (maximum to minimum) over which the inverted value varied, for an assumed (actual) value of the same parameter. In Figure 7, we show the inversion for free-water content. We note that the mean estimated value generally follows the assumed value, and lies on the 1:1 line. In Figure 7(a), the errorbars indicate the \pm 1 standard deviation values, while in Figure $7(\mathrm{~b})$, the errorbars indicate the total range. The \pm 1 standard deviation values are generally within $0.01(1 \%)$ of the actual value, while the error considering the total range of inverted values is acceptable ( $3-4 \%$ maximum, especially at lower values).

The inversion for surface roughness is shown in Figure 8 with similar errorbar representation, from which we observe that the errors are generally higher, relatively: of the order of $0.2 \mathrm{~mm}$ and $0.6 \mathrm{~mm}$ considering \pm 1 standard deviation and total range around the actual 


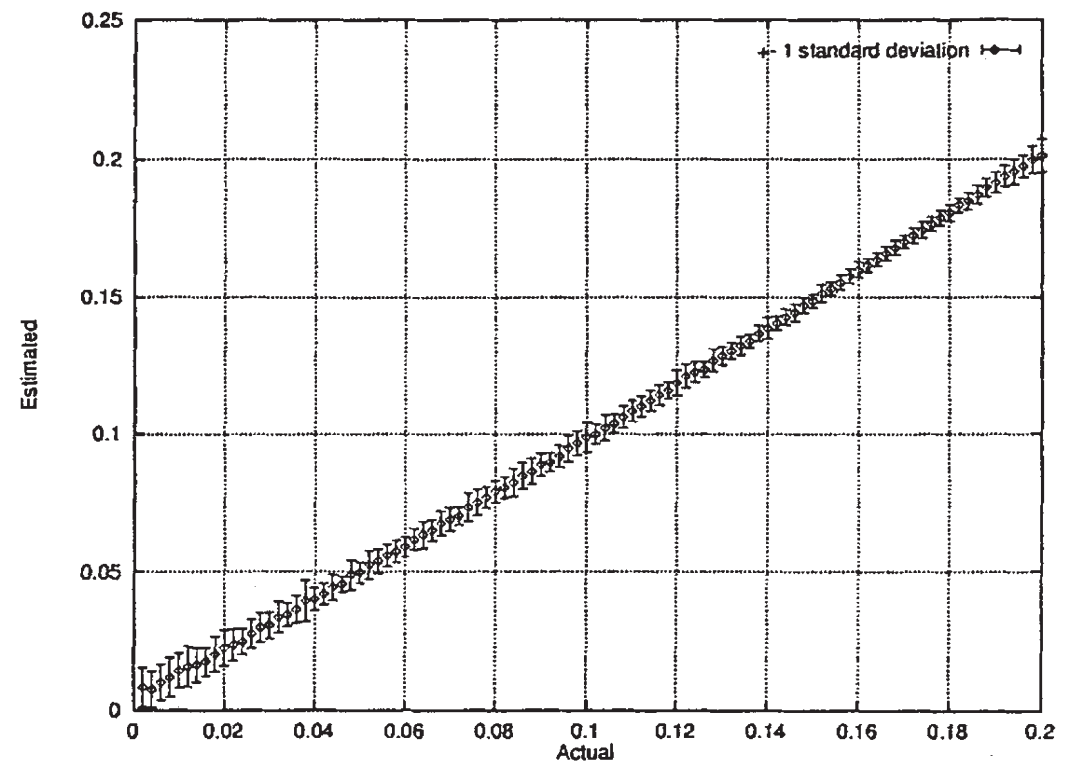

(a)

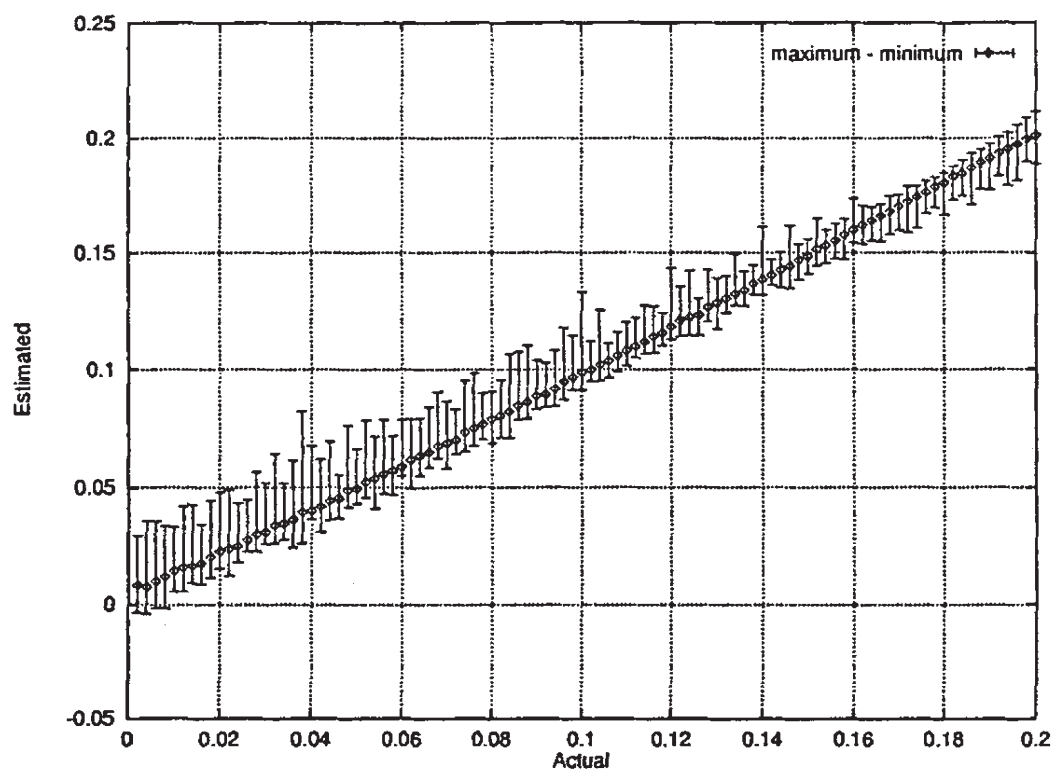

(b)

Figure 7: Inversion for free-water content under noise-free conditions, showing (a) \pm 1 standard deviation bounds, and (b) total range. 


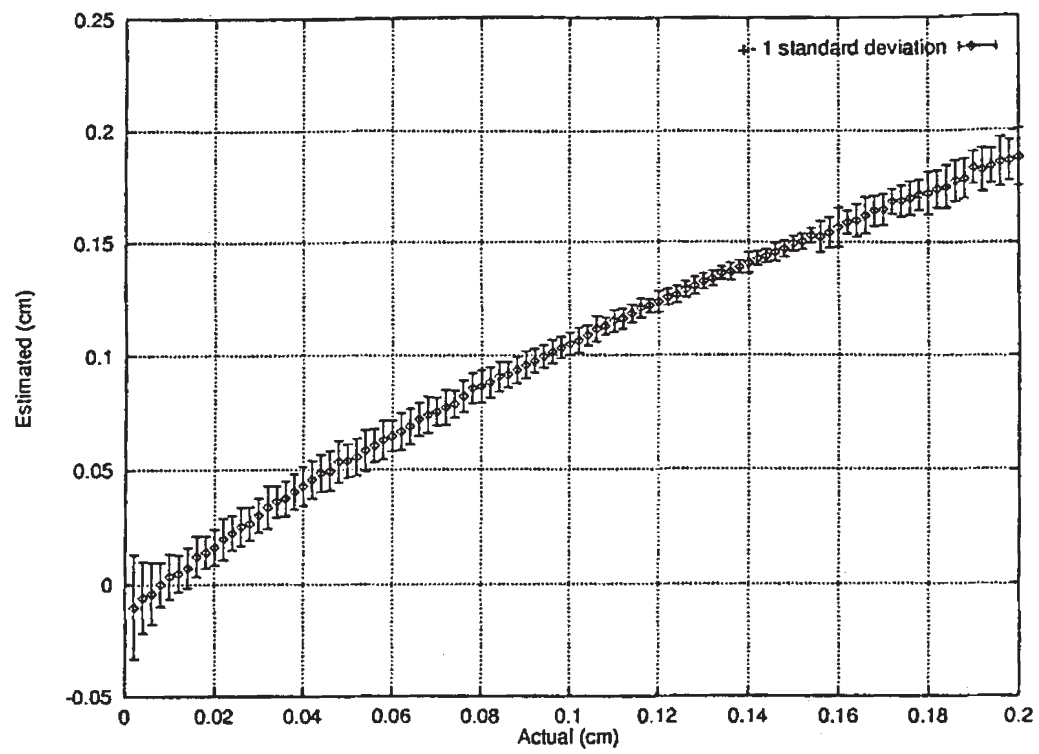

(a)

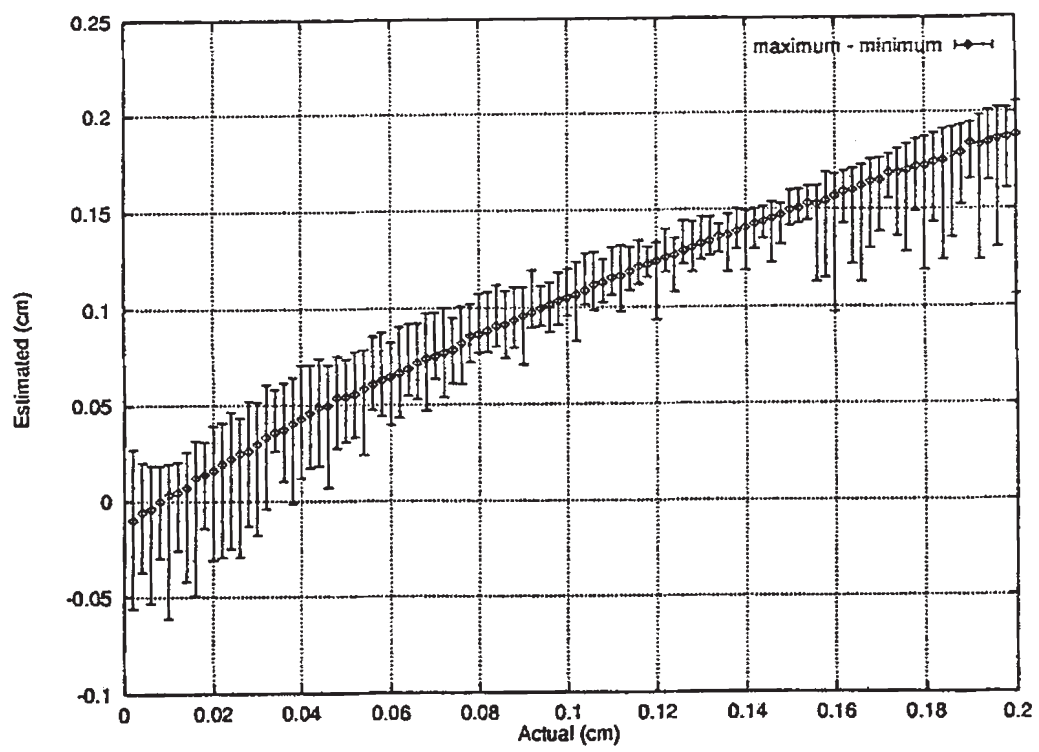

(b)

Figure 8: Inversion for surface roughness under noise-free conditions, showing (a) \pm 1 standard deviation bounds, and (b) total range. 
values respectively. However, these errors are within the expected range of variations in surface roughness in the field.

Figure 9 shows in a similar manner the results of the grain diameter inversion, with similar errorbar representation. The mean estimated values are seen to lie on the 1:1 line with respect to the assumed value. We also observe that the \pm 1 standard deviation results are virtually error-free compared to the actual values, while the total range error is within $0.15 \mathrm{~mm}$.

We conclude that the neural network algorithm developed does indeed succeed in providing acceptable inversion estimates in a noise-free environment.

(2) Noise-Added Conditions: Under operational conditions, a signal-to-noise ratio (SNR) value of infinity is seldom achieved. Noise is invariably present in the system, and its effect modifies the input to the network. It must be remembered that the weights and the bias values for the neural network are derived assuming noise-free conditions. In order to incorporate the effects of noise, we assume that each measurement (reflectance or backscatter) can be split into a noise-free component, and a component that includes the effects of noise. We write

$$
v(n)=S(A+k)
$$

where $v(n)$ is the n-th observation, $S$ is the signal amplitude, $A$ is the attenuation factor, and $k$ is given by

$$
k=\frac{\text { noise amplitude }}{\text { signal amplitude }}
$$

The parameter $k$ is determined according to the distribution of noise. We assume that the noise signal is a zero-mean Gaussian distributed random variable whose variance can be related to the SNR.

The distribution of the noise signal $v_{n}$ is given by

$$
p\left(v_{n}\right)=\frac{1}{\sqrt{2 \pi \psi^{2}}} \exp \left(\frac{-v_{n}^{2}}{2 \psi^{2}}\right)
$$

where $\psi^{2}$ is the noise variance. The relationship between SNR and $\psi^{2}$ is [30]

$$
S N R=\frac{A^{2}}{2 \psi^{2}}
$$




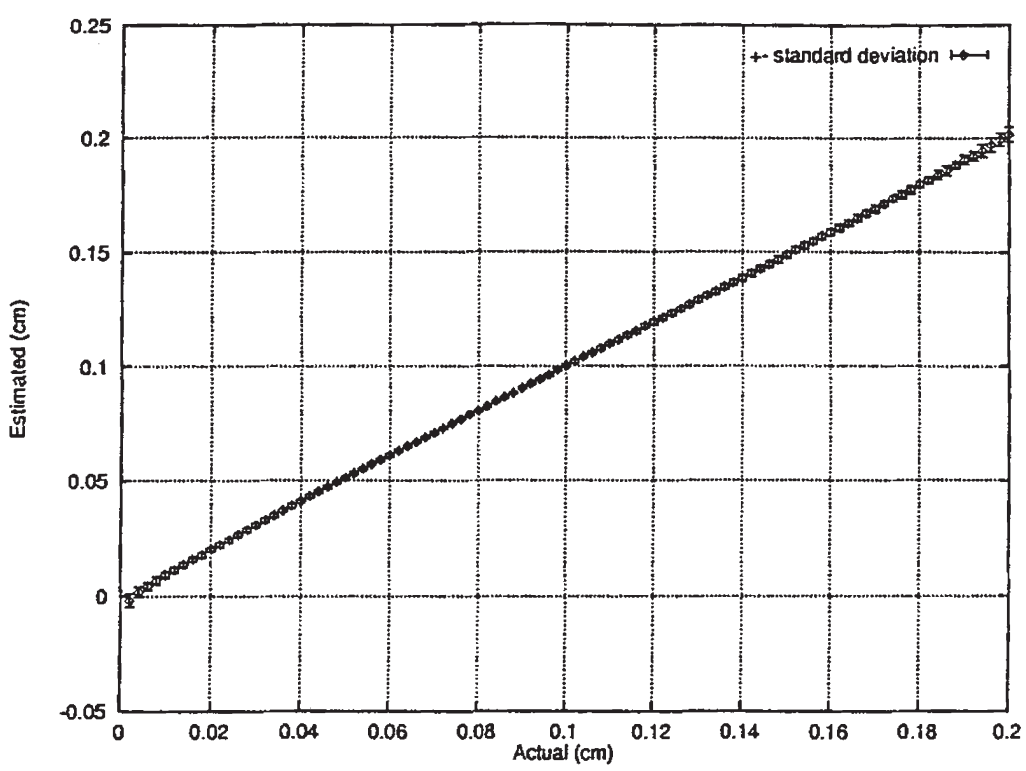

(a)

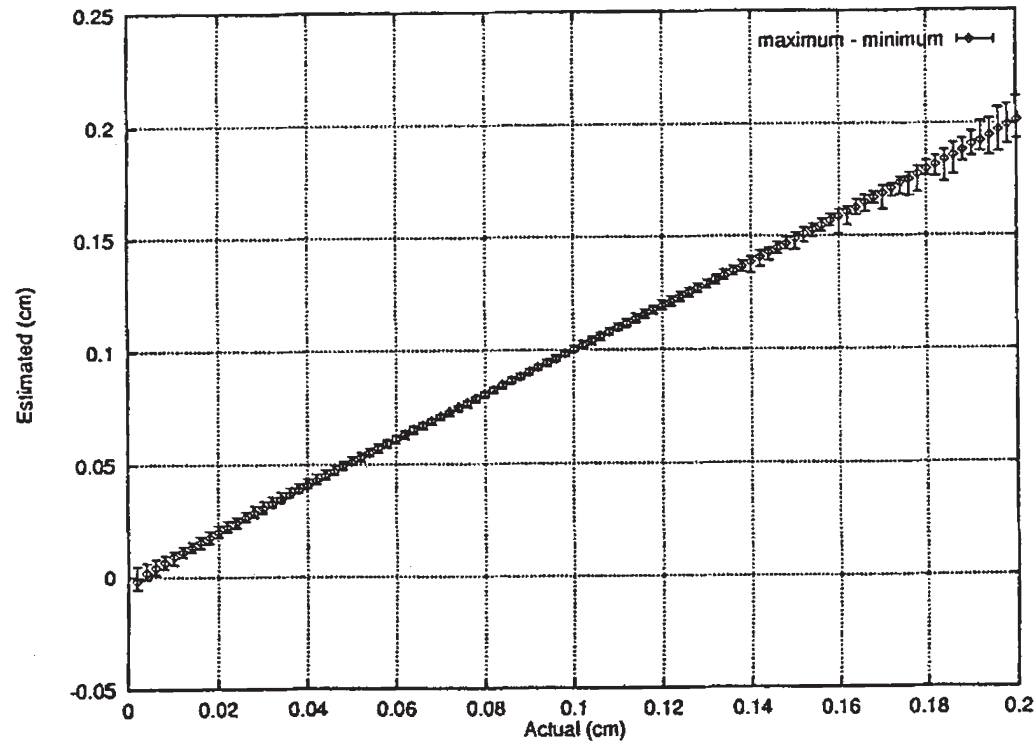

(b)

Figure 9: Inversion for grain diameter under noise-free conditions, showing (a) \pm 1 standard deviation bounds, and (b) total range. 
Thus, for a given combination of $A$ and $\psi^{2}$, the SNR can be computed. Alternately, for a given SNR, $A$ or $\psi^{2}$ can be determined if the other is known.

The performance of the inversion algorithm was evaluated for values of SNR ranging from $0 \mathrm{~dB}(1)$ to $60 \mathrm{~dB}(1000)$, as well as under noise-free conditions, i.e., infinite SNR. The value of $A$ was kept constant at 1.0 and corresponding $\psi^{2}$ values were computed. From the known values of $\psi^{2}$, various realizations of the noise signal amplitude were obtained by sampling the normal distribution described in Eqn. (20). After the noise-added data were generated for each measurement, appropriate ratios were formed to provide the inputs to the neural network.

For each output, the root-mean-squared (RMS) error was computed between the assumed value of the parameter and the inverted (estimated) value of the same parameter, for different SNR values. These results are plotted in Figures 10-12. Since large unacceptable errors occurred at SNR values between 0 and $20 \mathrm{~dB}$, the RMS error is shown only for SNR values greater than $20 \mathrm{~dB}$. As expected, the RMS errors are seen to decrease as SNR increases. The asymptotic straight line parallel to the $\mathrm{X}$-axis in each plot shows the RMS error under infinite SNR.

Based on acceptable values of the RMS error for each snow parameter, one can deduce the minimum SNR required from the plots. Alternately, one can fix SNR and determine the maximum RMS error achieved for each snow parameter. We considered as acceptable, RMS errors of $0.3 \mathrm{~mm}$ for grain size, $2 \mathrm{~mm}$ for surface roughness, and $2 \%$ for snow wetness. From the plots, we determined that corresponding minimum SNR values were approximately $27 \mathrm{~dB}, 32 \mathrm{~dB}$, and 29 $\mathrm{dB}$ respectively. Thus, an SNR value of greater than $32 \mathrm{~dB}$ provides acceptable errors in the surface snow parameter estimation using our neural network inversion algorithm.

\section{Conclusions}

In this paper, we have developed and tested a neural network inversion technique for remote estimation of free-water content, surface roughness, and grain diameter of fallen snow. The algorithm uses as inputs specific ratios derived from near-infrared reflectance and 


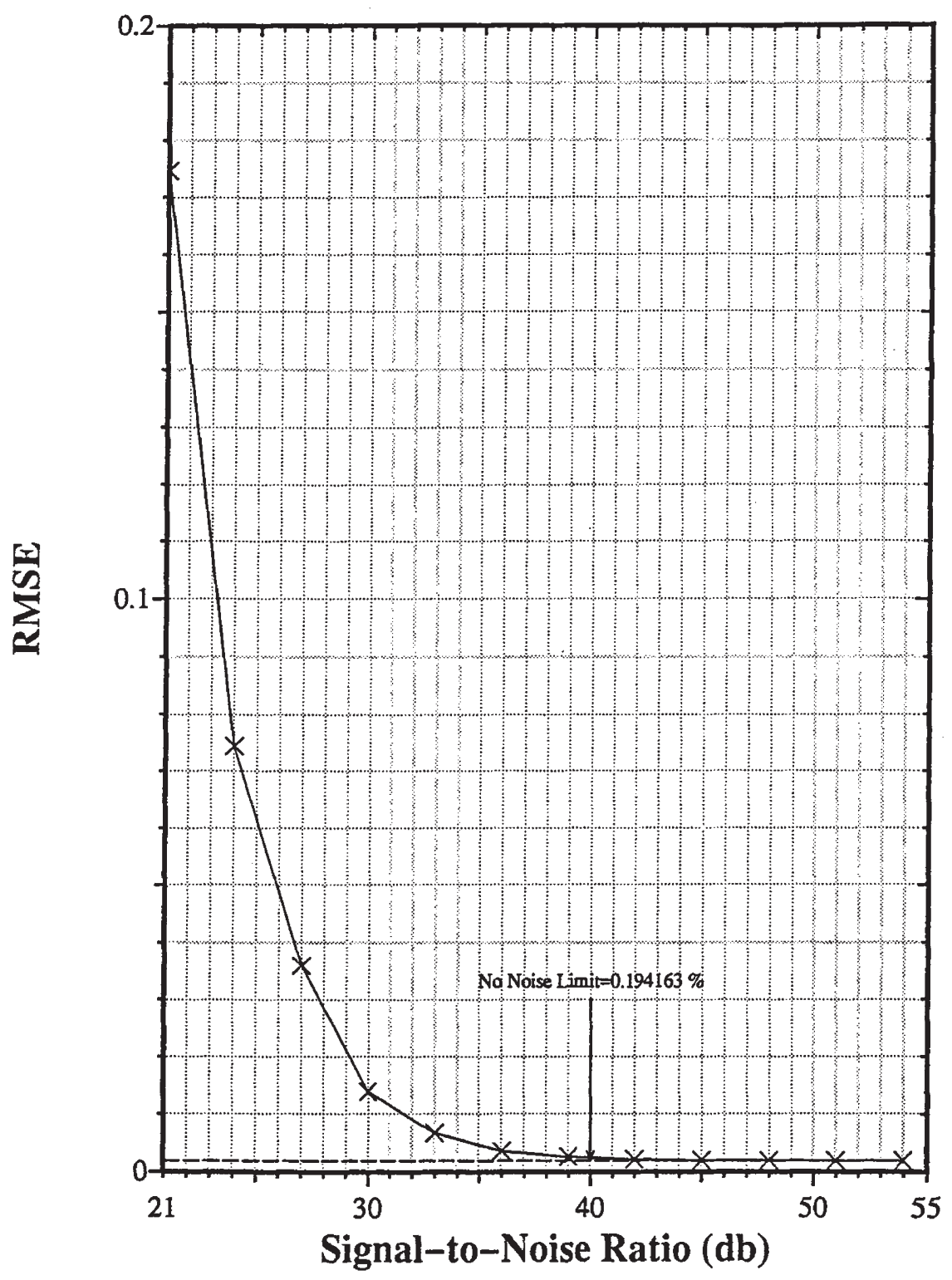

Figure 10: RMS error in free-water content as a function of SNR. 


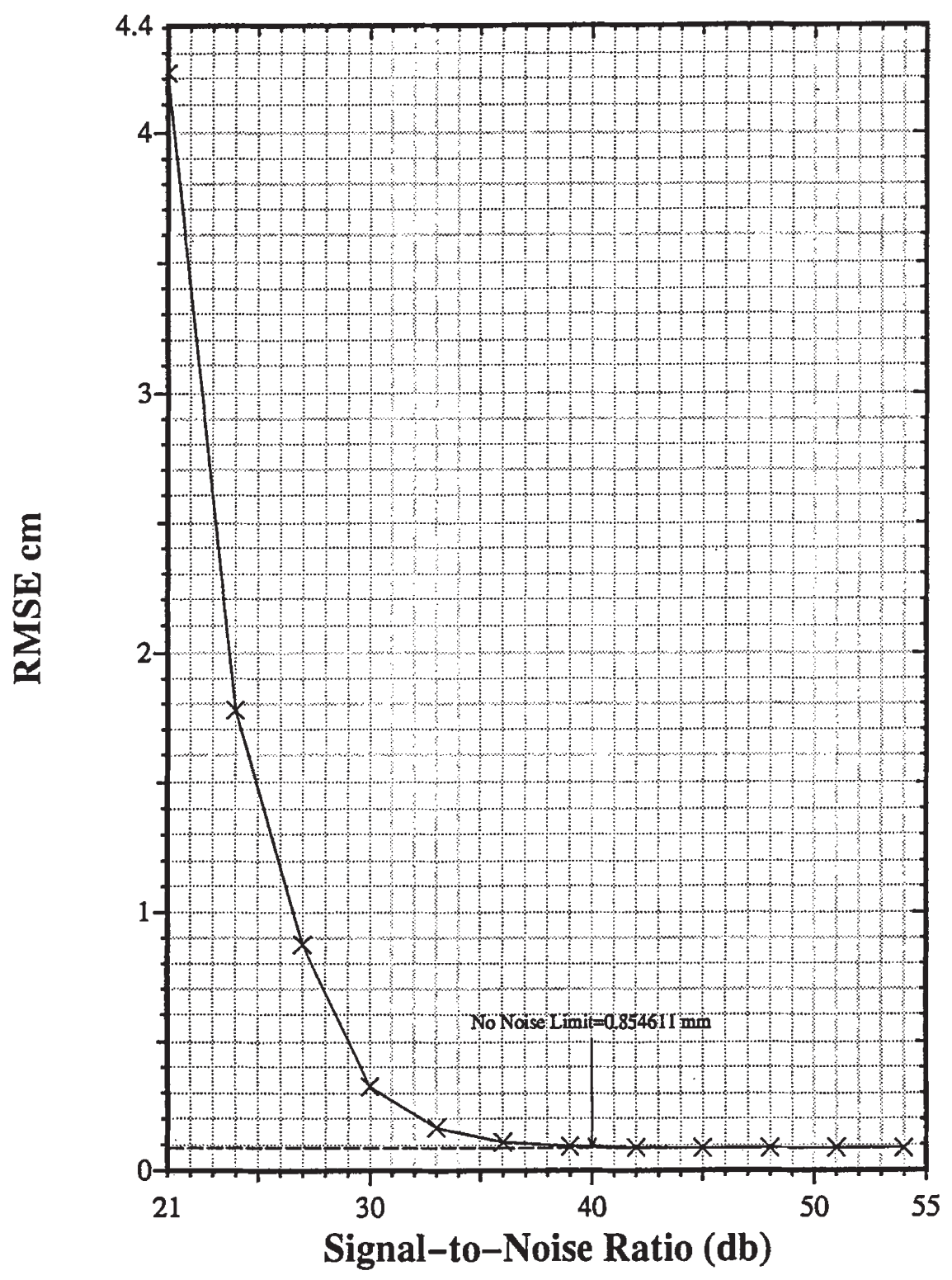

Figure 11: RMS error in surface roughness as a function of SNR. 


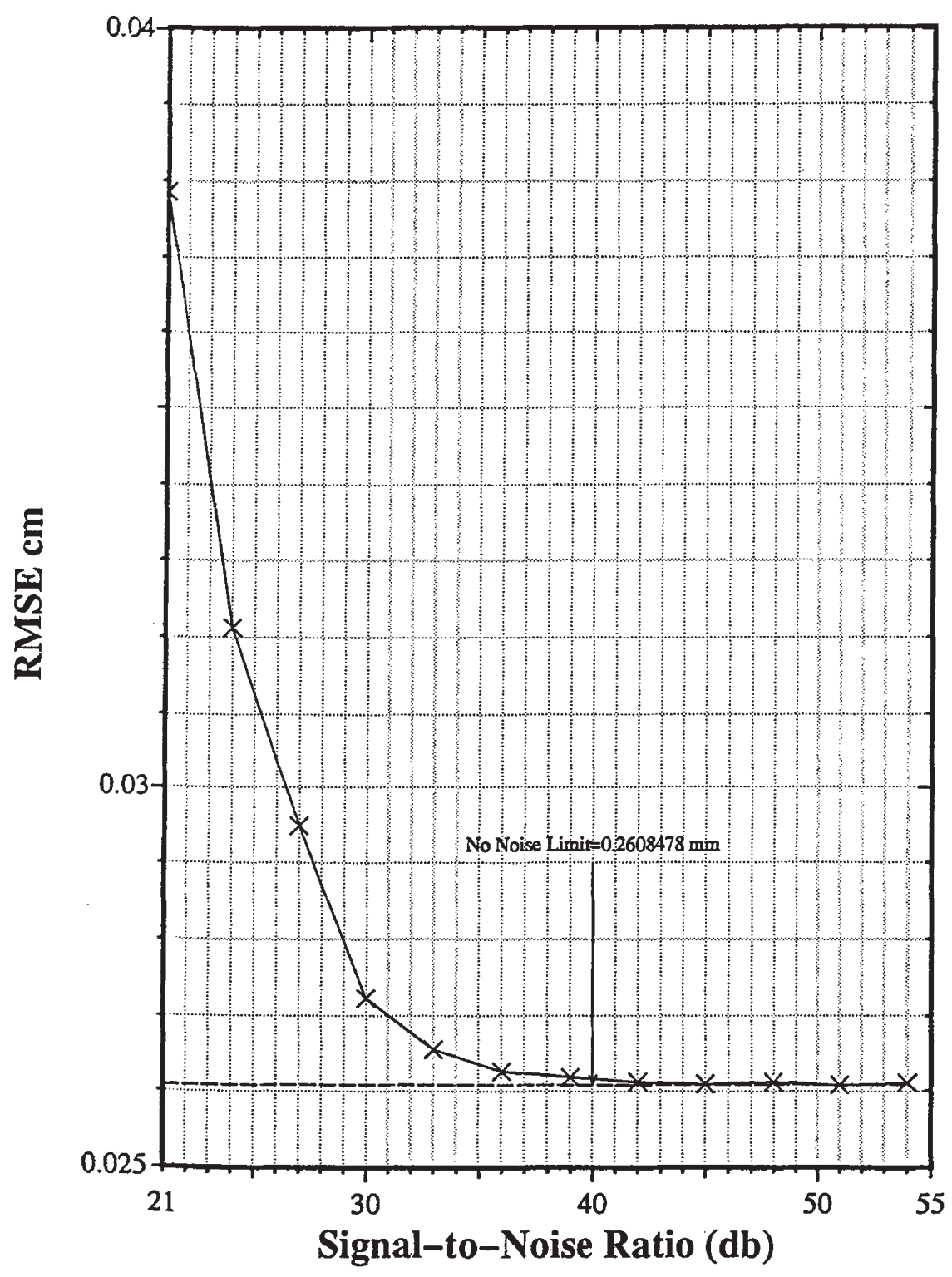

Figure 12: RMS error in grain diameter as a function of SNR. 
millimeter-wave backscatter. The use of ratios obviates the need for absolute calibration in an operational situation, if we assume that the atmospheric effects are the same for each measurement used to form the ratio. Although the algorithm has been trained using simple theoretical models, it can be adapted for specific geographical regions if corresponding measured data are available, and can also be generalized using more complicated models. Since the algorithm provides estimates of relevant surficial snow parameters, the evolution of snow metamorphism can be studied in space and time by airborne and, under certain ideal conditions, spaceborne sensors. Although the inversion is robust for high signal-to-noise ratios (greater than $32 \mathrm{~dB}$ ), it is important to understand that low signal-to-noise ratios of the sensors used to gather the data can hamper the meaningful estimation of the snow properties. A clearer understanding of the effects of noise on the inversion is required before any operational use of the algorithm.

\section{References}

[1] G. A. McKay and W. P. Adams, "Snow and living things," in HANDBOOK OF SNOW: PRINCIPLES, PROCESSES, MANAGEMENT, AND USE, D. M. Gray and D. H. Male (eds.), pp. 3-31. Toronto: Pergamon, 1981.

[2] M. O. Berry, "Snow and climate," in HANDBOOK OF SNOW: PRINCIPLES, PROCESSES, MANAGEMENT, AND USE, D. M. Gray and D. H. Male (eds.), pp. 32-59. Toronto: Pergamon, 1981.

[3] H. Steppuhn, "Snow and agriculture," in HANDBOOK OF SNOW: PRINCIPLES, PROCESSES, MANAGEMENT, AND USE, D. M. Gray and D. H. Male (eds.), pp. 60-125. Toronto: Pergamon, 1981.

[4] T. Schmugge (ed.), REMOTE SENSING OF SNOW AND EVAPOTRANSPIRATION. NASA Conference Publication 2363, 1985.

[5] D. K. Hall and J. Martinec, REMOTE SENSING OF SNOW AND ICE. London: Chapman and Hall, 1985.

[6] E. J. Langham, "Physics and properties of snowcover," in HANDBOOK OF SNOW; PRINCIPLES, PROCESSES, MANAGEMENT, AND USE, D. M. Gray and D. H. Male (eds.), pp. 275-337. Toronto: Pergamon, 1981. 
[7] S. C. Colbeck, "Classification of seasonal snow cover crystals," Water Resources Research, Vol. 22, No. 9, pp. 59S-70S, August 1986.

[8] T. Hyvarinen and J. Lammasniemi, "Infrared measurement of freewater content and grain size of snow," Optical Engineering, Vol. 26, No. 4, pp. 342-348, April 1987.

[9] A. Denoth, "The pendular-funicular liquid transition and snow metamorphism," Journal of Glaciology, Vol. 28, No. 99, pp. 357- 364, 1982.

[10] J. Dozier, S. R. Schneider, and D. F. McGinnis, Jr., “Effect of grain size and snowpack water equivalent on visible and near-infrared satellite observations of snow," Water Resources Research, Vol. 14, No. 4, pp. 1213-1221, August 1981.

[11] G. G. Gimmestad, "Analysis of snow ground truth data," Proc. Snow Symposium V, Hanover, NH, pp. 301-310, August 1985.

[12] W. J. Wiscombe and S. G. Warren, "A model for the spectral albedo of snow. I: Pure snow," Journal of the Atmospheric Sciences, Vol. 37, No. 12, pp. 2712-2733, 1980.

[13] J. H. Joseph, W. J. Wiscombe, and J. A. Weinman, “The Delta-Eddington approximation in radiative flux transfer," Journal of the Atmospheric Sciences, Vol. 33, No. 12, pp. 2452-2459, 1976.

[14] H. M. Nussenzveig and W. J. Wiscombe, "Efficiency factors in Mie scattering," Physical Review Letters, Vol. 45, No. 18, pp. 1490-1494, 1980.

[15] B. J. Choudhury and A. T. C. Chang, "On the angular variation of solar reflectance of snow," Journal of Geophysical Research, Vol. 86, No. CI, pp. 465-472, 1981.

[16] H. W. O'Brien and R. H. Munis, "Red and near-infrared spectral reflectance of snow," in OPERATIONAL APPLICATIONS OF SATELLITE SNOWCOVER OBSERVATIONS, A. Rango (ed.), NASA Special Publication 391, 1975.

[17] S: C. Colbeck, "Grain clusters in wet snow," Journal of Colloid and Interface Science, Vol. 72, No. 2, pp. 371-384, 1979.

[18] S. G. Warren and W. J. Wiscombe, "A model for the spectral albedo of snow. II: Snow containing atmospheric aerosols," Journal of the Atmospheric Sciences, Vol. 37, No. 12, pp. 2734-2745, 1980. 
[19] R. M. Narayanan and R. E. Mclntosh, "Millimeter-wave backscatter characteristics of multilayered snow surfaces," IEEE Transactions on Antennas and Propagation, Vol. 38, No. 5, pp. 693-703, May 1990.

[2o] Y. Kuga, F. T. Ulaby, T. F. Haddock, and R. D. DeRoo, "Millimeter-wave radar scattering from snow. 1: Radiative transfer models," Radio Science, Vol. 26, No. 2, pp. 329-341, March-April 1991.

[21] L. D. Williams, J. G. Gallagher, D. E. Sugden, and R. V. Birnie, “Surface snow properties effects on millimeter-wave backscatter," IEEE Transactions on Geoscience and Remote Sensing, Vol. 26, No. 3, pp. 300-306, May 1988.

[22] N. C. Currie, J. D. Echard, M. J. Gary, A. H. Green, Jr., T. L. Lane, and J. M. Trostel, "Millimeter-wave measurements and analysis of snowcovered ground," IEEE Transactions on Geoscience and Remote Sensing, Vol. 26, No. 3, pp. 307-318, May 1988.

[23] F. T. Ulaby, T. F. Haddock, R. T. Austin, and Y. Kuga, "Millimeter-wave radar scattering from snow. 2: Comparison of theory with experimental observations," Radio Science, Vol. 26, No. 2, pp. 343351, March-April 1991.

[24] R. M. Narayanan, "An empirical model for millimeter-wave backscatter from snow-covered ground," Proc. USNC/URSI Commission F Meeting, Boulder, CO, p. 22, January 1989.

[25] S. P. Lohmeier, P. M. Langlois, J. G. Colom, R. E. Davis, H. S. Boyne, and R. E. McIntosh, "A comparison of normalized cross section measurements and models for snow cover at 35, 95, and $225 \mathrm{GHz}$," Proc. IGARSS'92, Houston, TX, pp. 1655-1657, May 1992.

[26] S. Haykin, NEURAL NETWORKS: A COMPREHENSIVE FOUNDATION. New York: Macmillan, 1994.

[27] D. E. Rumelhart, G. E. Hinton, and R. J. Williams, "Learning internal representations by error propagation," in PARALLEL DISTRIBUTED PROCESSING: EXPLORATIONS IN THE MICROSTRUCTURE OF COGNITION, Vol. 1, D. E. Rumelhart and J. L. McClelland (eds.), pp. 318-362. Cambridge, MA: 1V[IT Press, 1986.

[28] L. Tsang, Z. Chen, S. Oh, R. J. Marks II, and A. T. C. Chang, "Inversion of snow parameters from passive microwave remote sensing measurements by a neural network trained with a multiple scattering 
model," IEEE Transactions on Geoscience and Remote Sensing, Vol. 30, No. 5, pp. 1015-1024, September 1992.

[29] D. T. Davis, Z. Chen, L. Tsang, J. N. Hwang, and A. T. C. Chang, "Retrieval of snow parameters by iterative inversion of a neural network," IEEE Transactions on Geoscience and Remote Sensing, Vol. 31, No. 4, pp. 842-852, July 1993.

[30] M. I. Skolnik, INTRODUCTION TO RADAR SYSTEMS. New York: McGraw-Hill, 1980. 